\title{
1 A Novel Understanding of Global DNA Methylation in Bobcat (Lynx rufus)
}

3 Bonnie Cantrell ${ }^{1 *}$, Sydney Friedman ${ }^{1 *}$, Hannah Lachance ${ }^{1}$, Chris Bernier $^{2}$ Brenda Murdoch ${ }^{3}$,

4 Stefano Frattini ${ }^{4}$, Andrea Talenti ${ }^{4,5}$, Paola Crepaldi4 ${ }^{4,6}$ and Stephanie McKay ${ }^{1}$

5 1Department of Animal and Veterinary Sciences, University of Vermont, Burlington, VT,

$6 \quad 05405$

$7 \quad$ 2Vermont Fish and Wildlife Department, Springfield, VT, 05156

8 3Department of Animal and Veterinary Science, University of Idaho, Moscow, ID, 83844

$9{ }^{4}$ Department of Veterinary Medicine, University of Milan, Milan, Italy

105 The Roslin Institute, University of Edinburgh, Easter Bush Campus, Midlothian, EH25 9RG,

11 United Kingdom

$12{ }^{6}$ Department of Agricultural and Environmental Sciences - Production, Landscape,

13 Agroenergy, University of Milan, Milan, Italy

$16 *$ Co-First Authors

18 Corresponding Author:

19 Email: Stephanie.McKay@uvm.edu

20 Phone: 802-656-2075

21 Fax: 802-656-8196 


\section{Abstract}

26 Epigenetic mechanisms may provide a novel prospective of bobcat (Lynx rufus) adaptation

27 to habitat loss/fragmentation. Previous research has focused on bobcat behavior and

28 genetics, but epigenetics has not been studied in bobcat. The aim of this study was to

29 determine the quantity of global DNA methylation in the liver of 30 bobcats. DNA was

30 extracted from liver samples obtained from the Vermont Fish and Wildlife Department. The

31 percent of global DNA methylation was quantified and calculated using the MethylFlash ${ }^{\mathrm{TM}}$

32 Methylated DNA 5-mC Quantification Kit from Epigentek (Farmingdale, NY). Age, sex, and

33 carcass weight data were collected at sampling and analyzed with percent of global DNA

34 methylation. Global DNA methylation was found to range from $0.46 \%$ to $2.76 \%$. Age ranged

35 from $<1$ to 12 years old and weight ranged from 3.18 to $13.61 \mathrm{~kg}$. Further analysis of

36 differential methylation may provide insight into novel means of bobcat conservation

37 within different regions of Vermont. These results reinforce the need for genome-wide

38 epigenetic studies in conservation biology.

40 Keywords: Conservation, Epigenetics, Felidae, Wildlife, Methylation

\section{Introduction}

43 Bobcats are at risk for population decline due to increased vulnerability to habitat

44 fragmentation, road mortality and habitat loss (Donovan et al. 2011;

45 Hunting_and_Trapping Vermont_Fish_and_Wildlife; Team 2015; Woolf et al. 2002). Genetic

46 research in bobcats thus far has been focused on identifying dispersal patterns and levels 
47 of genetic diversity within specific populations to understand the genetic effects of habitat

48 loss (Anderson et al. 2015; Diefenbach et al. 2015; Janecka et al. 2016; Janečka et al. 2007).

49 This use of genetic research has proven to be especially informative for conservation

50 management decisions (Allendorf et al. 2010). However, the use of epigenetics can allow

51 for greater comprehension of bobcat adaption to changing environmental conditions

52 (Allendorf et al. 2010).

53 Epigenetic modifications incorporate genetic and environmental interactions that affect

54 phenotypic variation. Epigenetics is described as the heritable change in gene expression

55 that occurs without a change to the nucleotide sequence (Ling and Groop 2009). DNA

56 methylation is a type of epigenetic modification classified as the addition of a methyl group

57 on the fifth position of a cytosine nucleotide resulting in a 5-methylcytosine (5-mC)

58 (Murphy et al. 2013). When DNA methylation is present in a gene promoter, it can inhibit

59 gene expression by preventing transcription factors and polymerases from binding to the

60 promoter (Dayeh et al. 2013). Methylation is variable and can differ between tissues

61 within the same individual as well as the same tissue can differ between individuals.

62 Factors that may influence DNA methylation include developmental stage, tissue type, age,

63 maternal diet, and habitat (Bird 2002).

64 The effect of DNA methylation in relation to weight and age in other species has been previously

65 studied. Takumi et al. (2015) found that feeding mice a methyl-deficient diet decreased mass due

66 to the lack of methionine and choline and promoted DNA demethylation patterns in the liver

67 (Takumi et al. 2015). Studies performed by both Bollati et al. in 2009 and Hannum et al. in 2013

68 determined that DNA methylation in the human genome decreases with age (Bollati et al. 2009;

69 Hannum et al. 2013b). The relationships between epigenetics, weight and age are unknown in 
70 bobcat, but are anticipated to be similar to mammalian epigenetic trends. However, diet and

71 weight has been shown to vary by sex, age, and maturity in bobcats and may contribute to

72 differential methylation between sex, age, and maturity. Litvaitis et al. found the diet of

73 mature bobcats and male bobcats consists more of deer than female and immature bobcats.

74 The differences in diet composition in bobcats may cause differential exposure to methyl

75 donors in the body and therefore promote differential DNA methylation between sex, age,

76 weight, and maturity.

77 Here we determine the percentage of global DNA methylation within the bobcat liver

78 epigenome. The primary objectives for this study are 1) to determine the percentage of

79 global DNA methylation within each bobcat liver genome and 2) examine and correlate the

80 differences in the percentage of global DNA methylation between bobcat age and carcass

81 weight of each bobcat liver sample. This novel study provides the first insight into global

82 DNA methylation in bobcat, which may facilitate a new direction for future conservation

83 research.

84

\section{Materials and Methods}

\section{Sample Collection}

87 Liver samples were collected from 30 bobcats that were harvested by trappers during the

88 2013/14 furbearer season in the state of Vermont. Carcasses were turned over to Vermont

89 Fish and Wildlife Department as part of the Furbearer project and age and weight were

90 collected (Hunting_and_Trapping Vermont_Fish_and_Wildlife). The samples consisted of 11 
91 males and 19 females with ages ranging from $<1$ to 12 years old. The carcass weights

92 ranged from 3.18 to $13.61 \mathrm{~kg}$ (Supplementary Table 1 ).

\section{Extraction and Global DNA Methylation Quantification}

94 DNA was extracted from 30 liver samples using a phenol-chloroform extraction process as

95 previously described (Sambrook et al. 1989). The concentration and quality of each DNA

96 sample was obtained using a NanoDrop spectrophotometer (Thermo Fisher Scientific,

97 Wilmington, DE) and the absence of sheared DNA was checked by gel electrophoresis using

98 50ng of DNA on a 1\% agarose gel.

99 To quantify the global amount of 5-mC within each liver DNA sample, 400ng of DNA for 100 each sample was sent to Epigentek and run on the Methylflash ${ }^{\mathrm{TM}}$ Methylated DNA 5-mC

101 Quantification Kit (Colorimetric) (Epigentek, Farmingdale, NY). At Epigentek, the samples

102 were quantified using a picogreen fluorescence method and were otherwise run with

103 standard conditions as described by Epigentek. Briefly, the 30 samples, 6 positive controls

104 (ranging from $0.2 \mathrm{ng} / \mu \mathrm{l}$ to $10 \mathrm{ng} / \mu \mathrm{l}$ ), and a negative control were run in duplicates. For

105 each sample, 50ng of DNA was bound to a plate, and fluorescently labeled for 5-mC

106 presence using various proprietary antibodies. The optical density of each sample was

107 recorded for the plate based on the amount of 5-mC florescence at $450 \mathrm{~nm}$. For each

108 positive control, the concentration was plotted by the optical density to create a standard

109 curve. The slope of the standard curve was determined using linear regression and was

110 used to determine the concentration of global 5-mC of each sample. Percent global DNA

111 methylation was determined by dividing the concentration of global 5-mC by 50ng and

112 multiplying by 100. 


\section{Statistical Analysis}

114 Statistical analyses were performed in JMP version 13, 2016 (SAS Cary, NC).

115 The Restricted Maximum Likelihood (REML) method was used to test for correlations

116 between DNA methylation, weight, age, sex, and maturity. A two-way analysis of variance

117 (ANOVA) was used to test for differences in the variation between DNA methylation by sex,

118 maturity, and sex and maturity interactions. The two-way ANOVA was then repeated for

119 age and weight for sex, maturity, and sex and maturity interactions. An analysis of

120 covariance (ANCOVA) for DNA methylation with age and weight as covariates were also

121 used to test for variation in DNA methylation by sex, maturity, and sex and maturity

122 interactions.

\section{Groupings}

124 Maturity of the male and female bobcats was classified as mature for $>2$ years old for male

125 bobcats and >1 year old for females (Crowe 1975; Fritts and Sealander 1978). One male

126 sample did not have an age score, but was classified as immature based on the light carcass

127 weight (Crowe 1975).

\section{Results}

\section{DNA Methylation}

130 Global measures of methylation detected in the bobcat liver ranged from $0.46 \%$ to $2.76 \%$

131 with an average methylation of 1.65\% (Supplementary Table 1 and Figure 1). The global 5-

$132 \mathrm{mC}$ measures ranged from $0.46 \%$ to $2.61 \%$ in females and $0.82 \%$ to $2.76 \%$ in males, $0.82 \%$

133 to $2.76 \%$ in immature bobcats independent of sex, and $0.46 \%$ to $2.61 \%$ in mature bobcats 
134 independent of sex. The average $\% 5-\mathrm{mC}$ was $1.70 \%$ in mature bobcat, $1.60 \%$ in immature

135 bobcat, $1.67 \%$ in female bobcat, and $1.61 \%$ in male bobcat (Table 1). No significant

136 differences were found in DNA methylation between each sex, maturity, or sex and

137 maturity interactions $(p<0.05)$ using an ANOVA or ANCOVA. The complete dataset can be

138 found in Supplementary Table 1.

141 The age of the bobcats ranged from 0 to 12 years and averaged 2.52 years (Figure 1 ). The

142 age of one mature male bobcat was older than the rest of the population (12 years) and

143 classified as an outlier. Male bobcats were significantly older than female bobcats

$144(p=0.013)$ with a range of 0 to 12 years and an average of 2.70 years. Female bobcats

145 ranged from 0 to 6 years and averaged 2.42 years. The average age was 4.27 years in

146 mature bobcats and 0.64 years in immature bobcats (Table 1). Mature bobcats were

147 significantly older than immature bobcats $(p<0.0001)$ and male mature bobcats were

148 significantly older than female mature bobcats $(p=0.048)$.

150 Weight

151 Bobcat weight ranged from 3.18 to $13.61 \mathrm{~kg}$ and averaged $6.87 \mathrm{~kg}$ (Figure 1). The weight of

152 two mature male bobcats was heavier than the rest of the population (12.7 and $13.61 \mathrm{~kg})$

153 and classified as outliers. Male bobcats were significantly heavier than female bobcats

$154(p=0.0001)$ with a range of 3.4 to $13.61 \mathrm{~kg}$ and an average of $7.86 \mathrm{~kg}$. Female bobcats

155 ranged from 3.18 to $7.71 \mathrm{~kg}$ and averaged $6.28 \mathrm{~kg}$. The average weight was $7.86 \mathrm{~kg}$ in

156 mature bobcats and $5.82 \mathrm{~kg}$ in immature bobcats (Table 1). Mature bobcats were 
157 significantly heavier than immature bobcats $(p<0.0001)$ and male mature bobcats were

158 significantly heavier than female mature bobcats $(p=0.0049)$.

160 Correlations

161 Restricted Maximum Likelihood (REML) method was used to determine the correlation

162 between phenotypes. Age and weight had a significant positive correlation $(\mathrm{p}<0.0001)$.

163 When outliers were excluded, the correlation remained significant and positive $(\mathrm{p}<0.007)$.

164 DNA methylation was not significantly correlated to age or weight ( $p>0.05)$. No correlation

165 was found between maturity and age, weight, or DNA methylation.

167 Discussion

168 This is the first report on DNA methylation in bobcat. However, DNA methylation has been

169 reported in other Felidae species. Global DNA methylation levels of $0.94 \%$ have been

170 reported for the liver methylome of Panthera uncia (snow leopard) (Jabbari et al. 1997).

171 These reports are similar to our results which found the bobcat liver epigenome to range

172 from $0.46 \%$ to $2.76 \%$ 5-mC (Figure 1). A report of the Felis catus (domestic house cat)

173 genome reported $10.5 \%$ of cytosines to be methylated in whole blood (Tamazian et al.

174 2014). This is also similar to what we found, but reported as percentage of methylation out

175 of total cytosines and our study reports methylation as a percentage of the entire genome.

176 While these previous studies on Felidae DNA methylation are based on a single animal, we

177 have reported DNA methylation in 30 bobcats. Here we show there is some variation in the

178 level of DNA methylation between individual bobcat with a standard deviation of $0.57 \%$ 
179 (Table 1). The genetic differences between species, tissue type and environment all can

180 contribute towards the observed variation in DNA methylation between Felidae. Variation

181 of methylation within the same tissue between animals and between tissues within the

182 same animal is highly documented (Bird 2002). Therefore, a portion of the observed

183 differences in global methylation between members of the family Felidae can be attributed

184 to the use of different tissue types in the different studies performed. However,

185 environmental differences of these three species may contribute towards considerable

186 variation in global DNA methylation levels.

187 Measurements of DNA methylation have been found to decrease with age in a variety of

188 species. Bollati et al. (2008) showed a gradual decrease in DNA methylation in the human

189 Alu transposable repetitive element over a span of eight years (Bollati et al. 2009).

190 Hannum et al. (2013) showed similar patterns in genome-wide DNA methylation and

191 showed methylation as strong biomarker of biological aging in humans (Hannum et al.

192 2013b). The consistent correlation between age and methylation was also reflected by

193 Teschendorff et al. (2013) who found correlations with the deregulation of DNA

194 methylation to age and correlations to the environmental factors driving methylation

195 deregulation early in life (Teschendorff et al. 2013). The adverse effect of age on DNA

196 methylation levels has been reported in reptiles. In a study performed by Parrott et al.

197 (2014), measures of global DNA methylation in blood was higher in juveniles compared to

198 adult American alligators (Alligator mississippiensis) (Parrott et al. 2014). Our results did

199 not find a correlation between methylation and age. However, our findings could be

200 influenced by a relatively small sample size of both the male and female bobcats and

201 unequal representation of age. Regardless, the trend in our findings are similar to those 
202 reported in mice, humans and rats (Unnikrishnan et al. 2018). In fact, the hypothesis that 203 global DNA methylation decreased with age was initially reported in 1988 (Zs-nagy et al.

204 1988) and advances since then have confirmed that there is an effect of aging on DNA

205 methylation but that effect is more likely to be seen at specific methylated cytosines or at

206 patterns of specific cytosine methylation as opposed to global measures of DNA

207 methylation. Further, changes in specific methylated cytosines have been utilized to

208 generate DNA methylation clocks to determine chronological and biological age of different

209 species. A majority of work regarding DNA methylation clocks has been performed in

210 humans (Hannum et al. 2013a; Horvath 2013; Unnikrishnan et al. 2019). Although, ages of

211 dogs and wolves are able to be estimated to within a year in dogs and wolves, using an

212 epigenetic aging clock (Thompson et al. 2017). As accuracy of these tools improve, it will

213 be interesting to realize the utility of aging clocks in wildlife populations and determine

214 their usefulness as a noninvasive means of determining age.

215 DNA methylation and weight can both be influenced by diet and home range size. A study

216 performed by Gittleman and Harvey (1982) showed in carnivores that the amount of flesh

217 in the animal's diet has a significant positive correlation to home range size (Gittleman and

218 Harvey 1982). There may be similar relationships in bobcat in which the home range size

219 affects diet composition and potentially the amount of methylation in the diet. Mature male

220 bobcats in Vermont have a home range of $70.9 \mathrm{~km}^{2}$, enabling them to access different

221 environments and consume different food sources than mature female bobcats, which have

222 the smaller home range of $22.9 \mathrm{~km}^{2}$ (Donovan et al. 2011). While male bobcats in Vermont

223 have a larger home range size than females, Donovan et al. also found that all bobcats

224 regardless of sex, age, or season stayed within $1 \mathrm{~km}$ of habitats with a greater prey density 
225 and cover (Donovan et al. 2011). The similar behaviors between bobcats of different sexes

226 and ages in regard to food proximity may allow for bobcats in Vermont to overall have a

227 similar level of methylation in their diets. This may explain why we did not find global DNA

228 methylation to differ by sex or age globally, but the resolution of DNA methylation in this

229 study may also not be enough to detect differences.

230 As the contribution of genetics and genomics towards conservation efforts has been

231 established, the role of epigenetic modifications to conservation efforts is just beginning to

232 be investigated. Loss of genetic diversity (Sheldon et al. 2018), outbreeding depression

233 (Bossdorf et al. 2008) and genotype-by-environmental interactions are among the factors

234 contributing to conservation that are regulated by both genetic and epigenetic

235 mechanisms. Environmental effects that have been studied in wildlife species and may

236 play a role in conservation efforts include mercury associated hypomethylation in polar

237 bear brains (Richard Pilsner et al. 2010) and heritable effects of DNA methylation relative

238 to paternal effects on adaption and anxious offspring in stickleback fish (McGhee and Bell

239 2014). Integration of genetic and epigenetic data, such as DNA methylation, may provide

240 connections between population genetics and genomics that have not been investigated

241 thus far (Allendorf et al. 2010). In order to eluciate the role of ecological epigenetics with

242 respect to conservation of wildlife species, additional epigenetics research needs to be

243 performed. This study found individal variation in DNA methylation in bobcats and, to the

244 best of our knowledge, is the first study to examine DNA methylation in bobcats.

\section{Acknowledgements}


This work was supported by the College of Agriculture and Life Sciences at the University

of Vermont. The authors would like to thank all of the individuals involve with the Vermont

Fish and Wildlife Department Furbearer Project.

\section{References}

252

253

254

255

256

257

258

259

260

261

262

263

264

265

266

267

268

269

270

271

272

273

274

275

276

277

278

279

280

281

282

283

284

285

286

Allendorf, F.W., Hohenlohe, P.A., and Luikart, G. 2010. Genomics and the future of conservation genetics. Nat Rev Genet 11(10): 697-709. doi:10.1038/nrg2844.

Anderson, C.S., Prange, S., and Gibbs, H.L. 2015. Origin and genetic structure of a recovering bobcat (Lynx rufus) population. Canadian Journal of Zoology 93(11): 889-899. doi:10.1139/cjz-2015-0038.

Bird, A. 2002. DNA methylation patterns and epigenetic memory. Genes \& Development 16(1): 6-21. doi:10.1101/gad.947102.

Bollati, V., Schwartz, J., Wright, R., Litonjua, A., Tarantini, L., Suh, H., Sparrow, D., Vokonas, P., and Baccarelli, A. 2009. Decline in genomic DNA methylation through aging in a cohort of elderly subjects. Mechanisms of ageing and development 130(4): 234-239.

Bossdorf, O., Richards, C.L., and Pigliucci, M. 2008. Epigenetics for ecologists. Ecology Letters 11(2): 106-115. doi:10.1111/j.1461-0248.2007.01130.x.

Crowe, D.M. 1975. Aspects of ageing, growth, and reproduction of bobcats from Wyoming. Journal of Mammalogy 56(1): 177-198.

Dayeh, T.A., Olsson, A.H., Volkov, P., Almgren, P., Ronn, T., and Ling, C. 2013. Identification of CpG-SNPs associated with type 2 diabetes and differential DNA methylation in human pancreatic islets [Research Support, Non-U.S. Gov't]. Diabetologia 56(5): 1036-1046. doi:10.1007/s00125-012-2815-7.

Diefenbach, D., Hansen, L., Bohling, J., and Miller - Butterworth, C. 2015. Population and genetic outcomes 20 years after reintroducing bobcats (Lynx rufus) to Cumberland Island, Georgia USA. Ecology and evolution 5(21): 4885-4895.

Donovan, T.M., Freeman, M., Abouelezz, H., Royar, K., Howard, A., and Mickey, R. 2011. Quantifying home range habitat requirements for bobcats (Lynx rufus) in Vermont, USA. Biological Conservation 144(12): 2799-2809.

Fritts, S.H., and Sealander, J.A. 1978. Reproductive Biology and Population Characteristics of Bobcats (Lynx rufus) in Arkansas. Journal of Mammalogy 59(2): 347-353. doi:10.2307/1379919.

Gittleman, J.L., and Harvey, P.H. 1982. Carnivore home-range size, metabolic needs and ecology. Behavioral Ecology and Sociobiology 10(1): 57-63.

Hannum, G., Guinney, J., Zhao, L., Zhang, L., Hughes, G., Sadda, S., Klotzle, B., Bibikova, M., Fan, J.-B., and Gao, Y. 2013a. Genome-wide methylation profiles reveal quantitative views of human aging rates. Molecular cell 49(2): 359-367.

Hannum, G., Guinney, J., Zhao, L., Zhang, L., Hughes, G., Sadda, S., Klotzle, B., Bibikova, M., Fan, J.-B., Gao, Y., Deconde, R., Chen, M., Rajapakse, I., Friend, S., Ideker, T., and Zhang, K. 2013b. Genome-wide Methylation Profiles Reveal Quantitative Views of Human 
Aging Rates. Molecular Cell 49(2): 359-367. doi:http://dx.doi.org/10.1016/j.molcel.2012.10.016.

Horvath, S. 2013. DNA methylation age of human tissues and cell types. Genome biology 14(10): 3156.

Hunting_and_Trapping, F. Vermont_Fish_and_Wildlife. http://www.vtfishandwildlife.com/hunt/furbearers and trapping/furbearer hunti ng and trapping.

Jabbari, K., Cacciò, S., Païs de Barros, J.P., Desgrès, J., and Bernardi, G. 1997. Evolutionary changes in $\mathrm{CpG}$ and methylation levels in the genome of vertebrates. Gene 205(12): 109-118. doi:http://dx.doi.org/10.1016/S0378-1119(97)00475-7.

Janecka, J.E., Tewes, M.E., Davis, I.A., Haines, A.M., Caso, A., Blankenship, T.L., and Honeycutt, R.L. 2016. Genetic differences in the response to landscape fragmentation by a habitat generalist, the bobcat, and a habitat specialist, the ocelot [journal article]. Conservation Genetics 17(5): 1093-1108. doi:10.1007/s10592-016-0846-1.

Janečka, J.E., Blankenship, T.L., Hirth, D.H., Kilpatrick, C.W., Tewes, M.E., and Grassman, L.I. 2007. Evidence for Male-biased Dispersal in Bobcats Lynx Rufus Using Relatedness Analysis. Wildlife Biology 13(1): 38-47.

Ling, C., and Groop, L. 2009. Epigenetics: a molecular link between environmental factors and type 2 diabetes [Research Support, Non-U.S. Gov't

Review]. Diabetes 58(12): 2718-2725. doi:10.2337/db09-1003.

McGhee, K.E., and Bell, A.M. 2014. Paternal care in a fish: epigenetics and fitness enhancing effects on offspring anxiety. Proceedings of the Royal Society B: Biological Sciences 281(1794): 20141146. doi:doi:10.1098/rspb.2014.1146.

Murphy, T.M., Mullins, N., Ryan, M., Foster, T., Kelly, C., McClelland, R., O'Grady, J., Corcoran, E., Brady, J., Reilly, M., Jeffers, A., Brown, K., Maher, A., Bannan, N., Casement, A., Lynch, D., Bolger, S., Buckley, A., Quinlivan, L., Daly, L., Kelleher, C., and Malone, K.M. 2013. Genetic variation in DNMT3B and increased global DNA methylation is associated with suicide attempts in psychiatric patients. Genes, brain, and behavior 12(1): 125-132. doi:10.1111/j.1601-183X.2012.00865.x.

Parrott, B.B., Bowden, J.A., Kohno, S., Cloy-McCoy, J.A., Hale, M.D., Bangma, J.T., Rainwater, T.R., Wilkinson, P.M., Kucklick, J.R., and Guillette, L.J. 2014. Influence of tissue, age, and environmental quality on DNA methylation in Alligator mississippiensis. Reproduction 147(4): 503-513. doi:10.1530/rep-13-0498.

Richard Pilsner, J., Lazarus, A.L., Nam, D.-H., Letcher, R.J., Sonne, C., Dietz, R., and Basu, N. 2010. Mercury-associated DNA hypomethylation in polar bear brains via the LUminometric Methylation Assay: a sensitive method to study epigenetics in wildlife. Molecular Ecology 19(2): 307-314. doi:10.1111/j.1365-294X.2009.04452.x.

Sambrook, J., Fritsch, E.F., and Maniatis, T. 1989. Molecular Cloning: A laboratory Manual. Cold Spring Harbor Laboratory Press, Plainview, New York.

Sheldon, E.L., Schrey, A., Andrew, S.C., Ragsdale, A., and Griffith, S.C. 2018. Epigenetic and genetic variation among three separate introductions of the house sparrow (Passer domesticus) into Australia. R Soc Open Sci 5(4): 172185-172185. doi: $10.1098 /$ rsos.172185.

Takumi, S., Okamura, K., Yanagisawa, H., Sano, T., Kobayashi, Y., and Nohara, K. 2015. The effect of a methyl-deficient diet on the global DNA methylation and the DNA 

Shevchenko, A., Brukhin, V., Cherkasov, N., Svitin, A., Koepfli, K.-P., Pontius, J., Driscoll, C.A., Blackistone, K., Barr, C., Goldman, D., Antunes, A., Quilez, J., LorenteGaldos, B., Alkan, C., Marques-Bonet, T., Menotti-Raymond, M., David, V.A., Narfström, K., and O'Brien, S.J. 2014. Annotated features of domestic cat - Felis catus genome. GigaScience 3(1): 13. doi:10.1186/2047-217x-3-13.

Team, V.W.A.P. 2015. Vermont Wildlife Action Plan 2015. Edited by V.F.W. Department, Montpelier, VT.

Teschendorff, A.E., West, J., and Beck, S. 2013. Age-associated epigenetic drift: implications, and a case of epigenetic thrift? Human Molecular Genetics 22(R1): R7-R15. doi: $10.1093 / \mathrm{hmg} / \mathrm{ddt} 375$.

Thompson, M.J., vonHoldt, B., Horvath, S., and Pellegrini, M. 2017. An epigenetic aging clock for dogs and wolves. Aging (Albany NY) 9(3): 1055-1068. doi:10.18632/aging.101211.

Unnikrishnan, A., Hadad, N., Masser, D.R., Jackson, J., Freeman, W.M., and Richardson, A. 2018. Revisiting the genomic hypomethylation hypothesis of aging. Annals of the New York Academy of Sciences 1418(1): 69-79. doi:10.1111/nyas.13533.

Unnikrishnan, A., Freeman, W.M., Jackson, J., Wren, J.D., Porter, H., and Richardson, A. 2019. The role of DNA methylation in epigenetics of aging. Pharmacology \& therapeutics 195: 172-185. doi:10.1016/j.pharmthera.2018.11.001.

Woolf, A., Nielsen, C.K., Weber, T., and Gibbs-Kieninger, T.J. 2002. Statewide modeling of bobcat, Lynx rufus, habitat in Illinois, USA. Biological Conservation 104(2): 191-198. doi:http://dx.doi.org/10.1016/S0006-3207(01)00164-1.

Zs-nagy, I., Cutler, R.G., and Semsei, I. 1988. Dysdifferentiation Hypothesis of Aging and Cancer: A Comparison with the Membrane Hypothesis of Aging. Annals of the New York Academy of Sciences 521(1): 215-225. doi:10.1111/j.17496632.1988.tb35280.x. 
Table 1: Descriptive Statistics for DNA Methylation, Age, and Weight in Bobcats

366 "Obs. No." is the number of observations for each category. "SD" is the standard deviation

367 and "SE" is the standard error. The 95\% confidence interval is reported as "CI 95\%" with

368 "LL" as the lower limit and "UL" as the upper limit.

\begin{tabular}{|c|c|c|c|c|c|c|c|}
\hline Measurement & Group & Obs. No. & Mean & SD & SE & Cl 95\% LL & Cl 95\% UL \\
\hline & Total & 30 & 1.65 & 0.57 & 0.1 & 1.44 & 1.86 \\
\hline & Female & 19 & 1.67 & 0.56 & 0.13 & 1.4 & 1.94 \\
\hline Methylation & Male & 11 & 1.61 & 0.6 & 0.18 & 1.21 & 2.02 \\
\hline (Percentage) & Immature & 15 & 1.6 & 0.62 & 0.16 & 1.26 & 1.94 \\
\hline & Mature & 15 & 1.7 & 0.53 & 0.14 & 1.4 & 1.99 \\
\hline & Total & 29 & 2.52 & 2.65 & 0.49 & 1.51 & 3.53 \\
\hline & Female & 19 & 2.42 & 2.01 & 0.46 & 1.45 & 3.39 \\
\hline \multirow{2}{*}{ Age (Years) } & Male & 10 & 2.7 & 3.71 & 1.17 & 0.04 & 5.36 \\
\hline & Immature & 14 & 0.64 & 0.84 & 0.23 & 0.16 & 1.13 \\
\hline & Mature & 15 & 4.27 & 2.58 & 0.67 & 2.84 & 5.69 \\
\hline & Total & 29 & 6.87 & 2.45 & 0.46 & 5.94 & 7.81 \\
\hline & Female & 18 & 6.28 & 1.37 & 0.32 & 5.59 & 6.96 \\
\hline & Male & 11 & 7.86 & 3.45 & 1.04 & 5.54 & 10.17 \\
\hline & Immature & 14 & 5.82 & 2.12 & 0.57 & 4.59 & 7.04 \\
\hline & Mature & 15 & 7.86 & 2.39 & 0.62 & 6.54 & 9.18 \\
\hline
\end{tabular}


377 Figure 1: Scatterplot of animals by their weight ( $\mathrm{x}$ axis) and age ( $\mathrm{y}$ axis), with their 378 methylation levels (color from red to dark blue) and sex (square size) 